\title{
CARE OF CHILDREN WITH A CHRONIC CONDITION IN PRIMARY CARE: CHALLENGES TO THE HEALTHCARE MODEL
}

\author{
Elysângela Dittz Duarteㄹ, Kênia Lara Silva², Tatiana Silva Tavares³, Corina Lemos Jamal Nishimoto4, Paloma \\ Morais Silva ${ }^{5}$, Roseni Rosângela de Sena ${ }^{6}$
}

\footnotetext{
${ }^{1}$ Ph.D. in Pediatric and Adolescent Health. Professor, Escola de Enfermagem, Universidade Federal de Minas Gerais (EE/UFMG). Belo Horizonte, Minas Gerais, Brazil. E-mail: elysangeladittz@gmail.com

${ }^{2}$ Ph.D. in Nursing. Adjunct Professor, EE/UFMG. Belo Horizonte, Minas Gerais, Brazil. E-mail: kenialara17@gmail.com

${ }^{3}$ Doctoral student, Graduate Program in Nursing, EE/UFMG. CNPq Scholarship. Belo Horizonte, Minas Gerais, Brazil. E-mail: tatianasilvatavares@gmail.com

${ }^{4}$ M.Sc. in Nursing. Betim, Minas Gerais, Brazil. E-mail: corinajamal@gmail.com

${ }^{5}$ Master's student, Graduate Program in Nursing, EE/UFMG. Belo Horizonte, Minas Gerais, Brazil. E-mail: palomamorais@ ymail.com

${ }_{6}^{6}$ Ph.D. in Nursing. Full Professor, EE/UFMG. Belo Horizonte, Minas Gerais, Brazil. E-mail: rosenisena@uol.com.br
}

\begin{abstract}
This is a qualitative study aiming to analyze the healthcare model for children with chronic conditions in Primary Health Care. The study subjects were nurses, nurse technicians and auxiliary nurses working in 16 basic health units in the city of Belo Horizonte, Minas Gerais. Data were collected through semi-structured interviews and later analyzed from the critical perspective, seeking to identify the common themes in the empirical material. Data revealed how primary health care professionals identified and reached children with chronic conditions, as well as how they presented the care actions performed. However, the development of a model of care for children with chronic conditions in primary health that considers their specific health needs constitutes a challenge. DESCRIPTORS: Chronic disease. Disabled children. Primary health care. Pediatric nursing.
\end{abstract}

\section{CUIDADO À CRIANÇA EM CONDIÇÃO CRÔNICA NA ATENÇÃO PRIMÁRIA: DESAFIOS DO MODELO DE ATENÇÃO À SAÚDE}

\begin{abstract}
RESUMO: Estudo de abordagem qualitativa como o objetivo de analisar o modelo de atenção que orienta o cuidado à criança em condição crônica na atenção primária à saúde. Os sujeitos foram enfermeiros, técnicos de enfermagem e auxiliares de enfermagem, atuantes em 16 unidades básicas de saúde, no município de Belo Horizonte, Minas Gerais. Os dados foram coletados por meio de entrevista com roteiro semiestruturado e analisados a partir da perspectiva crítica procurando-se identificar os temas comuns no conjunto do material empírico. Os dados permitiram apreender aspectos da organização dos profissionais das unidades básicas de saúde para identificar e captar criança em condição crônica, além de ações de cuidado para essas crianças. Contudo, verificaram-se desafios para a construção de um modelo que incorpore o cuidado à criança em condição crônica na atenção primária à saúde de forma a considerar suas singularidades e necessidades de saúde.
\end{abstract}

DESCRITORES: Doença crônica. Crianças com deficiência. Atenção primária à saúde. Enfermagem pediátrica.

\section{CUIDADO DE NIÑOS CON ENFERMEDADES CRÓNICAS EN LA ATENCIÓN PRIMARIA: RETOS DEL MODELO DE ATENCIÓN DE LA SALUD}

\begin{abstract}
RESUMEN: Se trata de un estudio cualitativo realizado con el objetivo de analizar el modelo de cuidados de niños con enfermedades crónicas en la atención primaria. Los sujetos del estudio fueron enfermeros, técnicos y ayudantes de enfermería de 16 Unidades Básicas de Salud de la ciudad de Belo Horizonte, Minas Gerais. Los datos se recogieron en entrevistas con guión semiestructurado y se analizaron desde la perspectiva crítica, buscando identificar temas en común dentro del material empírico. Los datos permitieron vislumbrar aspectos organizativos de los profesionales para identificar niños con enfermedades crónicas, además de acciones para su cuidado. Sin embargo, se comprobó que hay que enfrentar retos para establecer un modelo que incorpore cuidados de niños con enfermedades crónicas a la atención primaria de la salud considerando sus particularidades y necesidades específicas.
\end{abstract}

DESCRIPTORES: Enfermedad crónica. Niños con discapacidad. Atención primaria de salud. Enfermería pediátrica. 


\section{INTRODUCTION}

Chronic conditions during childhood can be defined as those of a biological, psychological or cognitive basis lasting or expected to last at least one year and producing or expected to produce one or more of the following sequelae for the child: limitation in function or activity; dependence on medication, special diet, medical technology, assistive devices or persons; and/or the need for health services beyond what is usual for a child of the same age. ${ }^{1}$

The increase of pediatric chronic conditions related to scientific and technological advances is as an epidemiological trend. ${ }^{2}$ Advances in neonatal care are noteworthy, which have notably reduced the mortality of newborns for congenital or perinatal problems, although they remain associated with the development of diseases. ${ }^{3-7}$ This change in the pediatric morbidity profile demands a reorganization of the way to meet the needs of these children, seeking continuity of care in order to ensure their quality of life.

Studies on the care of children with chronic conditions (CCC) regarding their needs $\mathrm{s}^{8-10}$ and the organization of health care services to meet them ${ }^{11-}$ ${ }^{12}$ are incipient, especially in Brazil. The results of national studies, and the experience in the local context, indicate that the care of these children in the context of primary care in the health system in Brazil is not organized.

The health care model can be understood, from a technical-care dimension, as a form of organization of knowledge and techniques in the work process to solve health problems that constitute the epidemiological profile of a given population, and to intervene on the historically constructed social care needs. ${ }^{13}$

Given the increased occurrence of chronic conditions, discussions about the care models show that the health care services should surpass organizational proposals aimed at treating acute problems. Although these problems are still relevant, because even chronic conditions have episodes of exacerbation, the care of long-term diseases should be valued. ${ }^{14}$

For this surpassing of acute care to occur, the implementation of the Care Model for Chronic Conditions (CMCC) in the Brazilian Unified Health System (SUS) is proposed, emphasizing that cultural changes are needed in the Family Health Strategy (FHS). ${ }^{15}$ The CMCC should be based on the following elements: evidence-based clinical guidelines, system of user identification, population stratification into subpopulations, registration of people with health conditions by risk, use of electronic health records with warning systems and feedback, individual care plans, supported self-care, clinical management tools, network coordination by the Primary Health Care (PHC), articulation with community organizations, among others. ${ }^{16}$

It should be noted that the care model focused on individual or curative therapeutic management is not able to meet users' needs. Therefore, the practices should be directed towards the comprehensiveness of the individual and for his quality of life in the community, by strengthening bonds fostered by light technologies. ${ }^{17}$ In this sense, the strength of CMCC is emphasized, a care model for chronic conditions that is consistent with the SUS proposal. ${ }^{15}$

In this context, the aim of the study was to analyze the healthcare model for children with chronic conditions in the Primary Health Care in the Brazilian Unified Health System, considering the work of nursing professionals.

\section{METHODS}

This was a qualitative, descriptive, exploratory study supported by the methodological theoretical framework of the Marxist dialectics, considering the principles of historicity and totality. This framework guided the approach to the studied phenomenon in a methodological, theoretical path that indicates the real dynamics in the society, contextualizing the historical process with its movement, provisional character and transformation. ${ }^{18}$

The inclusion criteria for the study subjects were: nursing professionals working in a Basic Health Unit Care (BHU) in the city of Belo Horizonte, Minas Gerais, which is linked to the family health team; and having children with chronic conditions in their coverage area.

The participants were included by identifying children with chronic conditions discharged from high-risk neonatal care units to one federal hospital and one philanthropic hospital in the city, in a study previously developed by the research group. In the present study, a documental analysis of the children and administration of the Questionnaire for Identification of Children with Chronic Conditions (QuICCC-R) were performed by telephone. This initial contact enabled the con- 
firmation of the chronic condition of the child and identification of the BHU and the family health team to which the child was referred, according to the territory adopted in the city. Professional nurses and unlicensed members of the nursing staff who made up the reference staff of the identified children were invited to participate. The study participants included 16 nurses, six nurse technicians, and three auxiliary nurses who worked in 16 BHU in the city. The number of unlicensed nursing staff was lower than the number of nurses, due to the absence of these staff members at the time of data collection.

The data were collected through semistructured interviews with questions about the identification of children with chronic conditions in the covered area and the care actions of the nursing team and other professionals related to these children. Data collection was interrupted after all districts were covered and saturation of information was observed.

Successive readings of the interview transcripts were performed to identify the significant statements considering the research objectives, which were organized according to their themes. They were described in articulation, followed by a reflection about the empirical material and theoretical referential, with further deepening of ideas and the establishment of relationships. ${ }^{18} \mathrm{In}$ this study the themes that allowed an explanation of the phenomenon, primary care nursing work in the care of children with chronic conditions, evidencing the health care model that has guided the work of these professionals. In the resulting presentation, some participants' statements are exemplified, encoded with the letters $\mathrm{N}$ for nurses, NT for nurse technicians and NA for nursing auxiliaries, followed by an Arabic numeral indicating the order of the interviews.

All stages of the research were performed in accordance with the regulatory guidelines for research involving human beings, Resolution 466/ 2012 of the National Health Council and the project was approved by an ethics committee, protocol n. 0004.0.439.203-10. All participants were informed about the objectives and purposes of the study and signed the informed consent form.

\section{RESULTS}

The study results allowed for grasping aspects that reveal the model that guides care of pediatric chronic conditions in primary care. The organization of care to this group was evidenced from the nursing professionals' statements about the actions to identify and reach the children, the set of actions for the development of care, and the various services that make up the care network and their articulations for the care of these children.

Children with chronic conditions in PHC are identified in prenatal appointments, through the work of the Community Health Agent (CHA) and professional responsible for hospital discharge. Telephone calls are made by a professional from the hospital where the child was a patient, reporting on the discharge and the need for continuity of care in the BHU, as expressed in the fragments of these statements: [...] the mother usually comes to prenatal appointments here at the unit, and when the child is born we already know her (N6.2); The CHA reaches the children. The CHA goes to the house, registers the child [...] (N9.2); the maternity hospital contacts us saying that a child was discharged, how she was discharged. In my team, for example, I go there, perform the first visit, see about the first aid, see how she came in from the hospital and bring her to the unit (N15.2).

The children are also most prevalently identified through spontaneous demand for care by the family in the BHU. In these cases, the family seeks the service to try to solve any identified health problem or to participate in programmed activities, such as vaccination and monitoring of growth and development. Some families seek the service to obtain necessary materials for care, as evidenced in the excerpts of these statements: the identification sometimes occurs during spontaneous demand. The population knows that there is a health care facility, so they seek us (N17.4); There are children here that are not with my team, we know that they have health insurance, but they get materials here in the health center. So we can reach these children (N6.2).

The electronic information system is recognized by one of the respondents as a clinical management tool, which enables obtaining information about children with a chronic health condition. The respondent revealed that the BHU manager informs and warns them of the registration of these children in the system: the system reports come to the manager or the admission system, the manager prints it and informs us of who is hospitalized [...] (N13.3).

With regard to reaching the children, the active search is also highlighted when the children and their families miss an expected appointment; the participation of the CHA is highlighted [...] with the community agent, following-up, monitoring 
those children that were born and their health conditions. Doing an active search to bring them to the unit when they miss appointments that were scheduled, newborn screening tests that were not performed, for example ... or delayed vaccination (N9.3).

Once the child is reached, different actions and strategies are performed to meet the CCC in the PHC. In general, care of these children is subject to the identification of the need for care by the health care professionals or by the family, which is sporadically performed through spontaneous demand without an established follow-up for the CCC group, beyond what is usual for the other children, as expressed by the respondents: [...] well, I think too much is left for the family, such as realizing any changes in this child and seeking us when the chronic condition is already established. There is no appointment every six months. There is no protocol to instruct us on that. [...] Following-up is really dependent on a status change of this child (N5.1). The study participants mentioned the lack of protocols or lack of knowledge about them to guide care for the CCC.

Recognition was evidenced by some professionals of the importance of differentiated care for the CCC, although this does not happen in a systematic way in the set of care actions for the child, and is not specific given the demands of this group: [...] so sometimes she [child with chronic conditions] doesn't even come ... she comes due to other demands. But this child must be looked at carefully. It's a different look from the other healthy children, whose growth and development is satisfactory, within the standards (N2.19.2).

It appears that the care is organized according to protocols and guidelines of the Ministry and the Departments of Health for the care of children, with individual appointments scheduled with the nurse and the pediatrician: [...] children are one month up to two years old, with periodic child care, so we interpolate. [...] and there are children, for example, in the case of chronic asthma ... every two months ... it is necessarily for them to see the pediatrician (N20.1.1).

However, the data showed that these services receive a high influx of users through spontaneous demand due to acute conditions, which overwhelms the professionals and impairs the performance of activities, scheduled appointments and preventive actions, which could benefit children with chronic conditions: the service flow that we have is too high .... and the user profile in the heal th care centers ... they impair functioning of the proposed model to do so. So the time we would have to perform this process we use to care for acute patients [...] (N1.11); [...] The challenge is also to integrate other activities, I think we could actually perform other actions for these children with chronic diseases. Not only individual appointments with the nurse or the pediatrician ... To perform other preventive actions and instructions together, which could be integrated (N22.11).

The overload caused by spontaneous demand affects the care for children with chronic conditions, which should be performed with professional support, but the responsibility is transferred to the family: sometimes we don't have the ability to provide adequate care. Because there are two auxiliaries in the team, you can't stay there all the time providing care. Unfortunately, part of the care is placed upon the family. [...] I still think we're a little deficient on care, I mean, perfect care (N3.2).

The home visit was identified as a tool used by professionals to monitor children. In the statements, the involvement of the $\mathrm{CHA}$, nurse, nurse technician, physician and dentist was reminded. In this process, the CHA is responsible for identifying the children's demands, whereas the nurse acts to prevent diseases and to provide health education: [...] the nurse in her role ... I see that we play a lot of the educational role [...] to avoid complications (N1.8).

The group of children with chronic conditions due to asthma, diabetes and malnutrition receives care and home visits more frequently, and requires more vigilance than other children. There's the "Wheezing child" for asthmatic children, we are more concerned about children with diabetes, we call, re-call more often... home visiting is more frequent. We have major concerns about monitoring the families of malnourished children, this patient with a chronic condition is different, for example, from those without any disease [...] (N1.3). However, challenges were found for the performance of home visiting related to work organization, such as transportation difficulties, because the means of transportation are insufficient, which makes home care difficult. We have a child, she is seven years old, she was born with severe CP [cerebral palsy] and has several sequelae. Nowadays she uses a nasogastric tube, has a gastrostomy, has a tracheostomy, she can't walk, can't speak, she's on oxygen [...] it turns out we lost our visiting car [...] so we haven't been able to go there so far to visit this child (NT6.1).

The data enabled learning that the discontinuity of care for CCC also occurs due to the lack of supplies and materials to meet their demands, which are sometimes distinguished from those of other children, such as a tube for aspiration, 
medicines and special food: Sometimes we don't have material resources. We have the basics to be able to care (N2.18). We lack expensive medication that they prescribe for the child, sometimes we don't have it available, we have to ask the Secretariat, everywhere. Because SUS requires paperwork to dispense it ... It's hard to get it. But it has improved a lot, improved a lot... (NT14.5).

The respondents recognized that involvement of other professionals is required to meet the needs of the CCC. They also mentioned that the care for some needs of these children goes beyond the existing resources at the BHU. In this context, they seek to identify ways to care for the children in the health care system, providing referral of the child.

For care service in the network, the establishment of a Regulatory System (SISREG) has facilitated the referral of children despite the difficulties in scheduling specialized consultations. The respondents associate this difficulty to the limited number of specialists in the network and high demands from the population [...] imagine the child needs a specialized appointment. Now there's a regulatory system that prioritizes it [...] but overall, it's kind of slow (NT10.1); Just the matter of the flow, having it in the network. Flows for appointments with specialists. They take a lot of time. Sometimes it's an urgent situation and it takes time because the queue is large and there are only a few professionals in the network (N9.7).

Moreover, the absence of a defined flow for referrals is reported, including those for the Nucleum for the Support to Family Health (NSFH), which is another difficulty: [...] I find it very difficult because there is a lack of flow guidance... referrals, where we should go [...] (N9.1).

Through the electronic information system, the professionals in the BHU can have access to information about other appointments for the child in the health care network, such specialized ones or hospital admissions, thereby enabling monitoring of the case. However, the statements show that the available electronic information system still does not allow for access to all appointments; difficulties remain for referral and counter-referral: [...] it's the old problem of referral and counter-referral. It ends up getting lost. It's always a child followed-up in neuro and gastro. You hardly have a counter-referral on that. Very few of the professionals have access to management [information systems] of the City Hall [...] (N5.2.1).

Given the difficulties of obtaining information, the professionals turn to communication with relatives of the child or to information obtained by the CHA: [...] and most of the time I get the mother to come and give me news, because I don't have the counter-referral, or the CHA performs the visit and brings me news, because the mother makes a pilgrimage through the city to meet all the child's needs (N2.5.1).

However, some respondents mentioned that, despite care being fragmented, the child has access to specialized care, according to her needs: [...] in the heal th care center it's still fragmented. But generally speaking, this child has care guaranteed in the network according to her needs (N11.1).

Regarding the inclusion of CCC in the health services network, one respondent recognized the importance of primary care in the service network, emphasizing their role to reach the CCC and to coordinate and articulate different care required by these children in their route through the different points of care: if we consider that primary care has to be the coordinator of care ... That it must follow all the families, all the children in the long run, I think that, although we have had a hard time reaching these children to be followed here in primary care, reaching them must occur as soon as possible (N17.8).

Despite the difficulties, it was possible to identify strategies adopted to coordinate the work of different professionals monitoring CCC by family health teams. The data show that this type of work is expressed and promoted through discussions among the FHS team members, as well as among the members of NSFH team and also among different pediatric health care services.

The spaces for discussion in the BHU identified by one of the respondents are: [...] staff meetings, health agents report case by case (NT18.2). At that time, the CHAs report every case individually so that other professionals can also know them.

In the monthly NSFH meetings with the FHS team professionals, the progression of the children is discussed and the care provided by each professional, as well as new cases that demand care. The respondents reported that in these meetings, matrix-based strategies are used to monitor specialists' instructions, with nurses, pediatricians, general practitioners and nurse technicians participating in this activity: [...] for example, to decide whether a child on an enteral diet should be referred to a gastroenterologist for a gastrectomy. This is all discussed in the team, appointments are scheduled, referrals are made to NSFH, external evaluations are requested (N5.4.2).

According to the respondents, the space for discussion organized with the NSFH provides ac- 
cess to information and better team performance for the continuity of care: [...] then it becomes a more regular service, you can manage it better (N5.2).

The Children's Forum was the space for dialogue out of the BHU, presented by one of the professionals as a possibility to direct and organize care for the CCC. According to the respondent, this Forum is a space where professionals from various areas meet to discuss the care for the children in the network. The professionals involved are nurses, pediatricians, psychologists and general physicians, but the Forum is open to all professionals caring for children. The meetings are regular and the professionals bring in demands and difficulties they have in their workplaces and in the care network. Then, agreements are made that allow for referrals to medical specialists or decisionmaking for the organization of care in the health care network.

It was also possible to establish the existence of team actions that push the boundaries of the health care facilities, seeking to favor care for CCC in other spaces, such as the school, as evidenced in the statement: [...] I went to the school principal to see how care was performed because the diet was offered in the school, water was offered in the school, sometimes the child had fever in the school (N2.15).

Despite cues of recognition by the professionals of the need for intersectoral actions for the care of CCC, they were considered challenging. The initiative of articulation with the educational sector was approached through the Healthy School Program, but it was emphasized that CCC require access to other services, with the need to establish partnerships with social work and tutoring assistance being mentioned. In addition to these, the urbanization-related services were highlighted by the need to provide the minimum conditions for child care at home, such as clean water, sewage and paving of streets, allowing for accessibility of the child/family to the services that they need.

\section{DISCUSSION}

Different practices have been reported for the daily care of CCC in the PHC. However, the professionals face challenges to the continuity of care as determined by the forms of organization of the service in the PHC, defined by a health care model that focuses on caring for acute conditions.

The actions offered by the professional who monitors growth and development, disease prevention and health promotion actions are performed during childcare appointments and groups in regard to some specific conditions, when children are assessed and families are instructed on the performance of home care. Therefore, it was found that although there are actions for the care of CCC, they do not differ from the set of programmatic actions proposed for other children in the PHC, and are not specific for the care of their needs. Although the existence of a protocol with specific guidelines does not guarantee effective care, it is a tool with the potential to guide care, which was not identified for children with chronic conditions in the PHC.

The attempt to stratify these children into groups for care was evidenced, however the various repercussions of their basic health problems that demand specific and continuing care are not considered beyond those performed when they are included in the groups proposed in the BHU. One example is the inclusion of children with cerebral palsy in a malnutrition or asthma group. These nutritional and pulmonary disorders commonly occur in patients with cerebral palsy, but there are other needs related to this condition, no less important, which sometimes do not receive due attention.

It is noteworthy that the primary pediatric health care that is generally met is that which is identified by the family through spontaneous seeking of care in the BHU. This identification can be incomplete, according to the family members' understanding of the health-disease process. Thus, the needs of these children cannot be perceived by family members and health care professionals, who define actions for only a partial and fragmented outcome, given an incomplete identification. ${ }^{19}$

This fragmented way to care for the CCC in the PHC allows their identification within the population's health statistics only according to their various illnesses and acute episodes, thereby impairing their recognition from the perspective of integrality and the offer of health care with the complexity and uniqueness of each child and his family. That has implications both for the organization of health care services and for the development of health policies for this group. Thus, the adoption of a comprehensive approach to deal with pediatric chronic conditions by policy makers, managers and health care professionals is defended, based on the consequences of these conditions and regardless of diagnostic categories. ${ }^{2}$ This approach will enable an expanded look, guided by the principle of integrality for these 
children, in recognition of the needs of the children and their families.

In addition, the data highlighted the challenges to the continuity of care for CCC in the PHC related to: a service demand that is higher than what is feasible given the number of professionals in the BHU; fragmented work of the health care team; inefficiency of referral and counter-referral; difficulty of intersectoral actions; insufficient logistical transport system, and; the lack of materials and technologies. Similar difficulties have been identified in other studies on work in the PHC. ${ }^{20-23}$

The fragmentation of care in the BHU and in the health care services network, as well as the lack of coordination of actions by the PHC professionals, are characteristics of the care model that compromise the continuity of care for CCC. ${ }^{22,24}$ There is the need to establish organized flows of referral and counter- referral for the integration of the network services ${ }^{24}$ in the care for the CCC. The inefficiency of this logistics network system is shown, which can result in redundant or disconnected actions. It is noteworthy that professionals have difficulty accessing information about the care offered to CCC, thereby requiring noninstitutional strategies in an attempt to obtain the necessary data.

Other studies ${ }^{20,25}$ reveal that the PHC has not been active in the organization of the Health System and the coordination of care, as recommended by the Ministry of Health, which leads to the reflection on the need to reassess its integration into SUS. For the PHC to be able to gradually expand its capacity to act effectively in the regulatory processes, consolidating its legitimacy with the users as having responsibility for the coordination of care, there must be investment in measures such as direct access of the teams to appointment scheduling, creation of formal and regular mechanisms of communication among professionals in the primary care network, and regulatory centers and qualification of micro regulatory processes in the units. ${ }^{20}$

The teamwork in the NSFH and in the Children's Health Forum was identified as an institutionalized strategy that contributes to the articulation of the work among professionals and the continuity of care at different levels of care. It is noteworthy that, although there are Forums all throughout the city, it was only mentioned by one of the respondents, perhaps because he was one of the referrals in the Forum. The NSFH meetings were also mentioned by a few professionals.
The strength of the CHAs was also highlighted due to their constant contact with the families, thereby being able to identify CCC and indicate the need for interventions. Thus, the $\mathrm{CHA}$ is an important mediator in the childcare network, facilitating the access of the child/family to the health care services. A study on the performance of the CHA with children and their families showed that there is a close relationship between them, and that the agents give instructions on infant feeding and childcare. Investment in the training of these professionals is essential, in addition to more integration with other professionals who make up the health care team. ${ }^{26}$

The data allow indicating the importance of a line of care focused on the needs of CCC and their families, in addition to investment in adequate therapeutic projects, network services that meet the demands, access to available care resources, action on the social determinants, and in the regulatory process. ${ }^{27}$

Starting from the recognition of the contributions of CMCC to the continuity of care for children with chronic conditions, cultural changes in the FHS are required based on information obtained in this study, by using tools and techniques to manage care and management processes so that results are achieved effectively and efficiently. Additionally, for the changes to occur, it is imperative that there is continuing education for the FHS teams. ${ }^{15}$

\section{FINAL REMARKS}

It was found that one of the reflections of the mode of organization of the services, in particular the lack of infrastructure and resources, is the fragmented way of providing care for the CCC that has been used in the health care network, usually guided by symptoms without considering the uniqueness of their conditions. The implications of these organizational issues must be recognized and analyzed by managers, professionals and users. The PHC must be configured as the most profitable space for the care of these children and their families, taking into account their realities and their health care needs.

Given the identified challenges, it is necessary to rethink the ability to offer actions to satisfy demands related to individual and collective treatment, rehabilitation, disease prevention and health promotion, thereby completing integrality. It is important to highlight the strength of the strategies to increase the understanding about the 
needs of CCC and the possibilities for care that provides these children and their families with a better quality of life.

Aspects of care for CCC in primary health care were highlighted with incipient and unsystematic approaches to elements of a model of care for chronic conditions. Although it is still not possible to change the logic that has guided care, a changing movement is detected, favoring integrality and continuity of care for CCC. The results are recognized to represent a singular reality; further research on this subject is important.

\section{REFERENCES}

1. Stein RE, Bauman LJ, Westbrook LE, Coupey SM, Ireys HT. Framework for identifying children who have chronic conditions: the case for a new definition. J Pediatr. 1993 Mar; 122(3):342-7.

2. Stein RE. The 1990s: a decade of change in understanding children with ongoing conditions. Arch Pediatr Adolesc Med. 2011 Oct; 165(10):880-3.

3. Markestad T, Kaaresen P, Ronnestad A, Reigstad H, Lossius K, Medbo S, et al. Early death, morbidity, and need of treatment among extremely premature infants. Pediatrics. 2005; 115(5):1289-98.

4. Moore T, Hennessy EM, Myles J, Johnson SJ, Draper ES, Costeloe KL, et al. Neurological and developmental outcome in extremely preterm children born in England in 1995and 2006: the EPICure studies. BMJ. 2012 Dec; 345:7961.

5. Miranda AM, Cunha DIB, Gomes SMF. A influência da tecnologia na sobrevivencia do recém-nascido prematuro extremo de muito baixo peso: revisão integrativa. REME Rev Min Enferm. 2010 Jul; 14(3):435-42.

6. Prigenzi M, Trindade C, Rugolo L, Silveira L. Fatores de risco associados à mortalidade de recém-nascidos de muito baixo peso na cidade de Botucatu, São Paulo, no período 1995-2000. Rev Bras Saúde Mater Infant. 2008; 8(1):93-101.

7. Victora CG, Aquino EML, Leal MC, Monteiro CA, Barros FC, Szwarcwald CL, et al. Lancet. 2011 May 28;377(9780):1863-76.Lancet. 2011 May 28; 377(9780):1863-76.

8. Nageswaran S, Silver EJ, Stein RE. Association of functional limitation with health care needs and experiences of children with special health care needs. Pediatrics. 2008 May; 121(5):994-1001.

9. Gavazza CZ, Fonseca VM, Silva KS, Cunha SR. Utilização de serviços de reabilitação pelas crianças e adolescentes dependentes de tecnologia de um hospital materno-infantil no Rio de Janeiro, Brasil. Cad Saúde Pública. 2008 May; 24(5):1103-11.

10. Neves ET, Cabral IE. A fragilidade clínica e a vulnerabilidade social das crianças com necessidades especiais de saúde. Rev Gaúcha Enferm. 2008 Jun; 29(2):182-90.

11. Meio MDBB, Magluta C, Mello RR, Moreira MEL. Análise situacional do atendimento ambulatorial prestado a recém-nascidos egressos das unidades de terapia intensiva neonatais no Estado do Rio de Janeiro. Ciênc Saúde Coletiva. 2005 Jun; 10(2):299307.

12. Viera CS, Mello DF. O seguimento da saúde da criança pré-termo e de baixo peso egressa da terapia intensiva neonatal. Texto Contexto Enferm. 2009 Mar; 18(1):74-82.

13. Paim JS. A reforma sanitária e os modelos assistenciais. In: Rouquayrol MZ. Epidemiologia \& saúde. Rio de Janeiro: MEDSI; 1994. p.455-66.

14. Organização Mundial da Saúde. Cuidados inovadores para condições crônicas: componentes estruturais de ação. Relatório Mundial. Genebra/ Brasil: OMS; 2003.

15. Mendes EV. O cuidado das condições crônicas na atenção primária à saúde: o imperativo da consolidação da estratégia da saúde da família. Brasília (DF): Organização Pan-Americana da Saúde; 2012.

16. Mendes EV. As redes de atenção à saúde. Brasília (DF): Organização Pan-Americana da Saúde; 2011.

17. Bonfada D, Cavalcante JLP, Araujo DP, Guimarães J. A integralidade da atenção à saúde como eixo da organização tecnológica nos serviços. Ciênc Saúde Coletiva. 2012 Fev; 17(2):555-60.

18. Minayo MCS. O desafio do conhecimento: pesquisa qualitativa em saúde. $12^{\mathrm{a}}$ ed. São Paulo (SP): Hucitec; 2010.

19. Araújo LFS, Bellato R, Hiller M. Itinerários terapêuticos de famílias e redes para o cuidado na condição crônica: algumas experiências. In: Pinheiro R, Martins PHN, organizadores. Avaliação em saúde na perspectiva do usuário: abordagem multicêntrica. Rio de Janeiro (RJ): CEPESC / IMS-UERJ; 2009. p. 203-14.

20. Baratieri T, Marcon SS. Longitudinality of care in nurses practice: identifying the difficulties and perspectives of change. Texto Contexto Enferm. 2012 Sep; 21(3):549-57.

21. Cecilio LCO, Andreazza R, Carapinheiro G, Araújo EC, Oliveira LA, Andrade MGG, et al. A Atenção Básica à Saúde e a construção das redes temáticas de saúde: qual pode ser o seu papel? Ciênc Saúde Coletiva. 2012 Nov; 17(11):2893-902.

22. Giovanella L, Mendonça MHM, Almeida PF, Escorel S, Senna MCM, Fausto MCR, et al. Saúde da família: limites e possibilidades para uma abordagem integral de atenção primária à saúde no Brasil. Ciênc Saúde Coletiva. 2009 May; 14(3):783-94.

23. Gomes FM, Silva MGC. Programa Saúde da Família como estratégia de atenção primária: uma realidade 
em Juazeiro do Norte. Ciênc Saúde Coletiva. 2011; 16(supl.1):893-902.

24. Feo JJO, Campo JMF, Camacho JG. La coordinación entre Atención Primaria y Especializada? Reforma del sistema sanitario o reforma del ejercicio profesional. Rev Adm Sanit. 2006; 4(2):357-82.

25. Pereira MJB, Curvo PA, Fortuna CM, Coutinho SS, Queluz MC, Campos LVO, et al. Avaliação das características organizacionais e de desempenho de uma unidade de Atenção Básica à Saúde. Rev Gaúcha Enferm. 2011 Mar; 32(1):48-55.

26. Ávila MMM. O Programa de agentes comunitários de saúde no Ceará: o caso de Uruburetama. Ciênc Saúde Coletiva. 2011 Jan; 16(1):349-60.

27. Malta DC, Merhy EE. O percurso da linha do cuidado sob a perspectiva das doenças crônicas não transmissíveis. Interface Comun Saúde Educ. 2010 Jul; 14(34):593-605. 